\title{
The Optimal Membrane Type for the Next Membrane Replacement of Tajoura SWRO Desalination Plant
}

\author{
Usama Ahmed Ezzeghni* \\ Department of Desalination Researches, Nuclear Research Center, Libya \\ * Corresponding author email: elzoghni@gmail.com
}

DOI: https://doi.org/10.21467/proceedings.4.37

\begin{abstract}
Desalination of seawater in Libya has the capability to increase the accessible resources for producing drinkable water. Desalination of seawater with reverse osmosis membrane technology is one of the most significant techniques in the field of seawater desalination, for the latter technique the membrane manufacturers had created a new advanced membranes that deliver a high output fresh water and high salt refusal that cause a decline in operating cost through lower energy consumption compared to the other thermal desalination technologies. This paper aims to compare between several membrane products developed by different companies to improve the productivity of Tajoura Seawater Reverse Osmosis (SWRO) Desalination plant with high quality fresh water. The membrane type SW30HRLE-440i was selected for the next membrane replacement, which increases the plant productivity from 12,000 to $14,300 \mathrm{~m}^{3} / \mathrm{d}$ with decreasing the number of membrane elements from 1080 to 900 membrane elements. In addition, the suggested membrane provides a high rejection, which results in an improved water quality with a salinity of less than 100 ppm where it was almost 200 ppm, as well as it allows the plant to be designed and operated at a lower operating cost through a reduced specific energy consumption, which was 8.492 to $5.48 \mathrm{kWh} / \mathrm{m}^{3}$ and can be less than 2 $\mathrm{kWh} / \mathrm{m}^{3}$ if a modern energy recovery device (ERD) is used with a significant modification to the plant.
\end{abstract}

Keywords: reverse osmosis; advanced membranes; low energy; high rejection, high quality.

\section{Introduction}

Reverse osmosis (RO) desalination technology has been well-known for more than three decades. Progressive advances in membrane materials and high energy saving through energy recovery devices have made modern $\mathrm{RO}$ process more attractive and economically competitive than other desalination technologies [1]. Due to increased consumption of fresh water in Libya and the noticed improvements of a reverse osmosis technology, it has led to increased demand of this technology locally and globally. Furthermore, identifying the future needs for desalination technology development, as well as a research and development activities that will result in cost-effective and more efficient desalination technologies that can

(C) 2018 Copyright held by the author(s). Published by AIJR Publisher in Proceedings of First Conference for Engineering

Sciences and Technology (CEST-2018), September 25-27, 2018, vol. 2.
This is an open access article under Creative Commons Attribution-NonCommercial 4.0 International (CC BY-NC 4.0)

license, which permits any non-commercial use, distribution, adaptation, and reproduction in any medium, as long as the

AijR original work is properly cited. ISBN: 978-81-936820-6-7 
meet the upcoming requirements [2]. In this paper Tajoura (SWRO) plant will be developed in parallel with the occurred developments of spiral wound membrane elements that permits desalination plants to be designed and operated to either lower operating cost through reduced energy consumption, or to decrease membrane replacement cost by increasing plant productivity at lower operating flux.

\section{Tajoura reverse osmosis plant}

The seawater desalination plant illustrated in figure 1 located at Tajoura on the Mediterranean coastline about $30 \mathrm{~km}$ east of Tripoli. The plant was planned to yield about 10,000 $\mathrm{m}^{3} /$ day of fresh water with a total dissolved solid of less than 200 milligrams per liter (ppm). The main purpose of the plant is to provide Nuclear Research Center (NRC) with an industrial and drinking water and to substitute the deficiency of drinking water at Tajoura city. It is consisting of a two passes. The first pass uses polyamide membranes to desalt seawater and the second pass is used to desalt the product of the first pass.

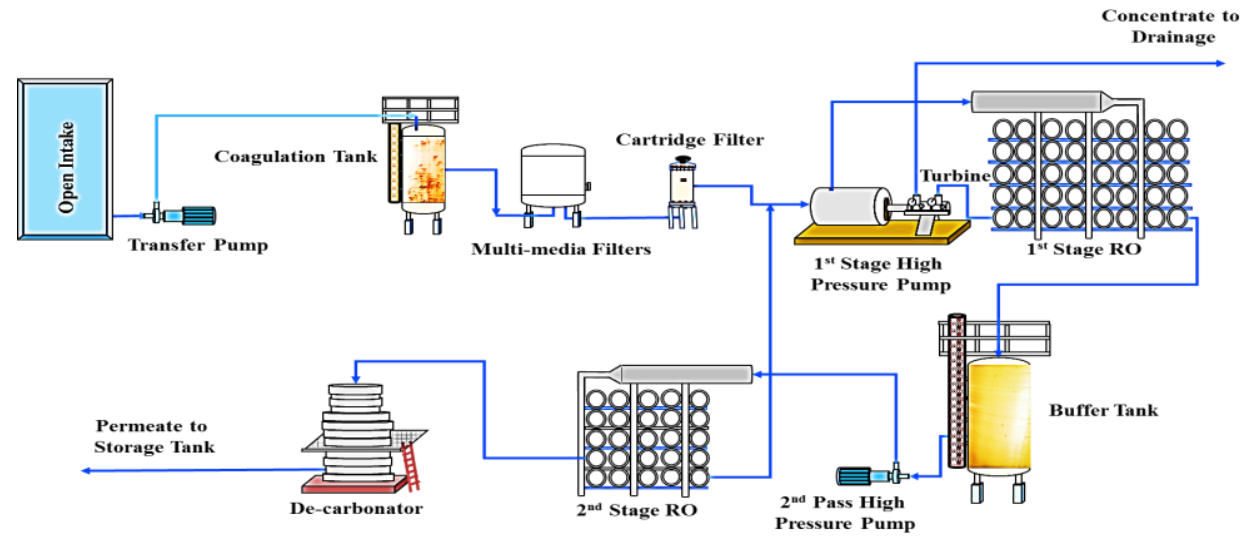

Figugre 1: Schematic diagram of the SWRO desalination plant.

Tajoura SWRO desalination plant with design parameters shown in table 1 [3], where seawater intake head is fitted at a distance of 1,300 $\mathrm{m}$ into the sea $7 \mathrm{~m}$ underneath the sea level and 6 $\mathrm{m}$ overhead the sea bottom. The feed water collected by gravity into a basin with a capacity of $5,580 \mathrm{~m}^{3}$ through two $760 \mathrm{~mm}$ diameter plastic pipes at the seashore, then $750 \mathrm{~m}^{3} / \mathrm{hr}(1,500$ $\mathrm{m}^{3} / \mathrm{hr}$ for $100 \%$ operation) are pumped to the pre-treatment side.

Table 1: The major design parameters of Tajoura desalination plant.

\begin{tabular}{|l|c|c|}
\hline Item & First stage & Second pass* \\
\hline Number of RO racks & 4 & 2 \\
\hline Pressure vessels (PVs) configuration & 1 stage & 3 stages (24-12-6) \\
\hline No. of PVs & 180 & 84 \\
\hline No. of membranes & 1080 & 504 \\
\hline
\end{tabular}

Proceedings of First Conference for Engineering Sciences and Technology (CEST-2018), vol. 2 
The Optimal Membrane Type for the Next Membrane Replacement of Tajoura SWRO Desalination Plant

\begin{tabular}{|l|c|c|}
\hline \hline No. of membranes per PV & 6 & 6 \\
\hline Nominal diameter, inch & 8 & 8 \\
\hline Membrane model & TFC 2822SS-360 & TFC 8600 PA \\
\hline Design pressure, bar & 82.8 & 41 \\
\hline Working pressure, bar & 54 & 31 \\
\hline $\mathrm{pH}$ & $5-6$ & $5-6$ \\
\hline Maximum temperature, ${ }^{\circ} \mathrm{C}$ & 45 & 45 \\
\hline Feed flow, $\mathrm{m}^{3} / \mathrm{d}$ & 34,285 & 552 \\
\hline Permeate flow, $\mathrm{m}^{3} / \mathrm{d}$ & 12,000 & 426 \\
\hline Concentrate flow, $\mathrm{m}^{3} / \mathrm{d}$ & 22,285 & 84 \\
\hline Design salt rejection, $\%$ & 99.6 & 98 \\
\hline Recovery, $\%$ & 35 & 85 \\
\hline Permeate salinity, $\mathrm{mg} / \mathrm{L}$ & $>200$ & 170 \\
\hline
\end{tabular}

*The second pass of the plant was not included in this study because the drinking water specifications can be achieved by the first stage only.

The pre-treatment contains an online coagulation-flocculation tank, 8-media filters and $5 \mu \mathrm{m}$ cartridge filters. Some chemicals are added before the feed water reaches the coagulation flocculation tanks. The chemicals are anti-scalants, which are injected to decrease scales accumulation, sulphuric acid used for $\mathrm{pH}$ adjustment, Copper sulphate as a disinfectant, sodium hydrogen sulphite for removing chlorine residue if added and ferric chloride sulphate for flocculation.

The pre-treated feed water then is fed to the RO assembly. The RO assembly consists of two passes. The first stage or pass contains four racks with a high-pressure pump for each. The pre-treated water exit from the cartridge filters is fed to first stage by means of four high pressure pumps coupled to a recovery turbine to recover about $30 \%$ of its energy requirement. The permeate of the first pass is collected in two inter-connected buffer tanks, and then it is fed to two racks of a second pass by mean of two other high-pressure pumps.

The product of the first stage is recovered by $85 \%$ using the second pass and collected in an intermediate tank for further post treatment. The brine stream from the second pass is recycled back and combined with the feed water of the first stage after the cartridge filter. The product will be sent through a degasifier for removing carbon dioxide and the final product treated by sodium hydroxide for $\mathrm{pH}$ adjustment and chlorinated by calcium hypochlorite before reaching the final storage tank [4].

\section{A comparison between suggested membrane elements}

Several membrane types developed by different manufacturers were evaluated based on commercially available $\mathrm{RO}$ process design softwares to predict the performance of Tajoura SWRO plant, optimizing membrane selection and operating conditions. Additionally, an estimation of water production quantity and quality from a given input parameters. Such of 
these programs are FilmTec (ROSA), Hydranautics (IMSDesign) and Toray Industries (TorayDS).

Table 2: Comparison between suggested and installed membranes.

\begin{tabular}{|l|c|c|c|c|}
\hline Company Name & Koch & Toray & Hydranautics & DOW Filmtec \\
\hline Design software & & TorayDS & IMS design & ROSA \\
\hline Configuration & 1 stage & 1 stage & 1 stage & 1 stage \\
\hline No. of PVs & 180 & 150 & 150 & 150 \\
\hline No. of membranes & 1,080 & 900 & 900 & 900 \\
\hline No. of membranes per PV & 6 & 6 & 6 & 6 \\
\hline Nominal diameter, inch & 8 & 8 & 8 & 8 \\
\hline Membrane model & TFC 2822SS- & $\begin{array}{c}\text { TM820V- } \\
440\end{array}$ & SWC6 MAX & $\begin{array}{c}\text { SW30HRLE- } \\
440 \mathrm{i}\end{array}$ \\
\hline $\begin{array}{l}\text { Max. operating pressure, } \\
\text { bar }\end{array}$ & 360 & 83 & 83 & 83 \\
\hline Working pressure, bar & 52.8 & 53 & 50.8 & 54.92 \\
\hline pH & 8 & 8 & 8 & 8 \\
\hline Maximum temperature,oC & 45 & 45 & 45 & 45 \\
\hline Feed flow, ${ }^{3} / \mathrm{d}$ & 34,285 & $34,285.7$ & $34,285.7$ & $34,285.71$ \\
\hline Permeate flow, $\mathrm{m}^{3} / \mathrm{d}$ & 12,000 & 12,000 & 12,000 & $12,000.12$ \\
\hline Design salt rejection, $\%$ & 99.6 & 99.8 & 99.6 & 99.7 \\
\hline Recovery, $\%$ & 35 & 35 & 35 & 35 \\
\hline Permeate salinity, mg/L & $>200$ & 164.6 & 276.1 & 98.92 \\
\hline Feed salinity, mg/L & 36,204 & $37,978.26$ & $37,980.65$ & $37,993.95$ \\
\hline
\end{tabular}

A permeate salinity goal of less than $300 \mathrm{mg} / \mathrm{L}$ was achieved for all the suggested membranes. Table 2 shows a performance comparison of different membranes to validate high productivity, less salt passage, lower energy consumption that will contribute in reduction of the unit water cost of Tajoura SWRO plant. The membranes and the suppliers related to are listed below:

- DOW Filmtec (SW30HRLE-440i);

- Toray and (TM820V-440), and

- Hydranautics (SWC6 MAX).

\section{Unit product cost}

The unit product cost decreased continuously over the years due to developments occurred in membrane productivity with less energy consumption. An economic evaluation analysis was achieved based on the calculation done by Element Value Analysis (EVA) tool that has been added to ROSA 9.1 program. The attained results are shown in table 3, which show very close values of the capital estimation of membrane elements, energy expenses, membrane 
The Optimal Membrane Type for the Next Membrane Replacement of Tajoura SWRO Desalination Plant

replacement expense, operating expense and the water cost net present value (NPV). The earlier expenses were calculated in parallel with optimization of Tajoura SWRO plant. The following parameters should be taken into considerations:

- Production capacity $\left(\mathrm{m}^{3} / \mathrm{h}\right)=500\left(12,000 \mathrm{~m}^{3} / \mathrm{d}\right)$

- Permeate recovery $(\%)=35$

- $\quad$ Interest rate $(\%)=8$

- $\quad$ Power cost (L.D. $\mathrm{kWh})=0.068$

The plant lifetime expected to be 25 years according to the latest refurbishment done by a Canadian company Jadmedic in 1998 [3], an interest rate of $8 \%$ and unit power costs of 0.068 L.D./kWh. All estimations based on common market prices in early 2016.

Table 3: Estimated water cost.

\begin{tabular}{|c|c|c|c|}
\hline \multicolumn{4}{|l|}{ Projection Results } \\
\hline Permeate production $\left(\mathrm{m}^{3} / \mathrm{h}\right)$ & 500 & 500 & 500 \\
\hline Feed pressure (bar) & 53 & 50.8 & 54.92 \\
\hline Concentrate pressure (bar) & 52 & 49.3 & 53.37 \\
\hline Recovery (\%) & 35.00 & 35.00 & 35.00 \\
\hline \multicolumn{4}{|c|}{ Capital Expense } \\
\hline Membrane Model & TM820V-440 & SWC6 MAX & $\begin{array}{l}\text { SW30HRLE- } \\
440 \mathrm{i}\end{array}$ \\
\hline Company Name & $\begin{array}{c}\text { Forever Pure } \\
\text { Place }\end{array}$ & $\begin{array}{l}\text { Forever Pure } \\
\text { Place }\end{array}$ & Watersurplus \\
\hline Total elements & 900 & 900 & 900 \\
\hline Element cost (\$/element) & 975.00 & 846.40 & 754.00 \\
\hline Capital for elements $(\$)$ & 877500.00 & 761760.00 & 678600.00 \\
\hline Capital $\left(\$ / \mathrm{m}^{3}\right)$ & 0.01 & 0.01 & 0.01 \\
\hline \multicolumn{4}{|c|}{ Operating Expense } \\
\hline Pumping power $(\mathrm{kW})$ & 2703.20 & 2639.7 & 2741.6 \\
\hline Pump specific energy $\left(\mathrm{kWh} / \mathrm{m}^{3}\right)$ & 5.47 & 5.28 & 5.48 \\
\hline Brine energy recovery $\left(\mathrm{kWh} / \mathrm{m}^{3}\right)$ & -122.41 & -122.41 & -122.41 \\
\hline Net energy consumption $\left(\mathrm{KWh} / \mathrm{m}^{3}\right)$ & 127.88 & 127.69 & 127.89 \\
\hline Net energy cost $(\$ / y r)$ & 22851893.03 & 22816832.14 & 22851893.03 \\
\hline $\begin{array}{l}\text { Energy expense NPV (Net Present } \\
\text { Value) (\$) }\end{array}$ & 203288847.88 & 243564576.44 & 243938843.61 \\
\hline Energy expense $\left(\$ / \mathrm{m}^{3}\right)$ & 86.96 & 86.82 & 86.96 \\
\hline \multicolumn{4}{|c|}{ Membrane replacement cost } \\
\hline Replacement rate $(\% / y r)$ & 15 & 15 & 15 \\
\hline Replacement price (\$/element) & 975.00 & 846.40 & 754.00 \\
\hline Replacement cost for elements $(\$ / y r)$ & 131625.00 & 114264.00 & 101790.00 \\
\hline replacement membrane NPV (\$) & 1405067.42 & 1219742.63 & 1086585.47 \\
\hline Membrane replacement expense $\left(\$ / \mathrm{m}^{3}\right)$ & 0.32 & 0.28 & 0.25 \\
\hline
\end{tabular}


Usama Ahmed Ezzeghni, CEST-2018, AIJR Proceedings 4, pp.697-703, 2018

\begin{tabular}{|l|c|c|c|}
\hline \hline \multicolumn{4}{|c|}{ Operating expense subtotal } \\
\hline Operating expense NPV $(\$)$ & 245343911.02 & 244784319.07 & 245025429.08 \\
\hline Operating expense per $\mathrm{m}^{3}$ & 87.28 & 87.10 & 87.20 \\
\hline \multicolumn{4}{|c|}{ Total } \\
\hline Cost NPV $(\$)$ & 877500.00 & 761760.00 & 678600.00 \\
\hline Life Cycle Cost $\left(\$ / \mathrm{m}^{3}\right)$ & 0.01 & 0.01 & 0.01 \\
\hline \multicolumn{4}{|c|}{ Total System } \\
\hline Operating expense NPV $(\$)$ & 245343911.02 & 244784319.07 & 245025429.08 \\
\hline Cost of water NPV $\left(\$ / \mathrm{m}^{3}\right)$ & 2.25 & 2.24 & 2.24 \\
\hline
\end{tabular}

\section{$5 \quad$ Results and discussion}

DOW Filmtec (SW30HRLE-440i) was selected as a candidate membrane for the next membrane replacement because the permeate salinity is $98.92 \mathrm{ppm}$, which was the lowest permeate salinity achieved compared by the other membranes. Furthermore, the number of membrane elements of the first stage were decreased from 1080 to 900 elements, thus, decreasing the next membrane replacement cost and / the number of throwing away membranes. Consequently, the number of pressure vessels of the first stage can be decreased from 180 to 150 (30 PVs extra), as well as the first stage racks are decreased from four racks to three racks. The earlier results don't include the second pass of the plant. Therefore, the second pass can be used for any other purposes.

If the extra 30 pressure vessels are comprised, the product capacity can be increased from $12,000 \mathrm{~m}^{3} / \mathrm{d}$ to $14,300.15 \mathrm{~m}^{3} / \mathrm{d}$ with a salinity of $99.59 \mathrm{mg} / \mathrm{L}$, which is still smaller than the salinity achieved by the first stage of the current installed membranes taken into consideration the feed pressure within 54-55 bar, see detailed design results in table 4. Finally, the specific energy consumption decreased from 8.492 to 5.48 , then to $5.47 \mathrm{kWh} / \mathrm{m}^{3}$, if the extra PVs are used, the earlier results are not including ERD and can be less than $2 \mathrm{kWh} / \mathrm{m}^{3}$ if modern ERDs are used.

Table 4: Detailed design results of using all the extra pressure vessels of the $1{ }^{\text {st }}$ stage

\begin{tabular}{|l|c|c|c|}
\hline Company Name & Koch & DOW Filmtec & DOW Filmtec \\
\hline Design software used & & ROSA & ROSA \\
\hline Configuration of PVs & 1 stage & 1 stage & 1 stage \\
\hline No. of PVs & 180 & 150 & 180 \\
\hline No. of membranes & 1,080 & 900 & 1,080 \\
\hline No. of membranes per PV & 6 & 6 & 6 \\
\hline Nominal diameter, inch & 8 & 8 & 8 \\
\hline Membrane model & TFC 2822SS- & SW30HRLE- & SW30HRLE- \\
& 360 & $440 \mathrm{i}$ & $440 \mathrm{i}$ \\
\hline
\end{tabular}


The Optimal Membrane Type for the Next Membrane Replacement of Tajoura SWRO Desalination Plant

\begin{tabular}{|l|c|c|c|}
\hline \hline Max. operating pressure, bar & 82.8 & 83 & 83 \\
\hline Working pressure, bar & 55 & 54.92 & 54.77 \\
\hline Feed flow, $\mathrm{m}^{3} / \mathrm{d}$ & 34,285 & $34,285.71$ & $40,857.14$ \\
\hline Permeate flow, $\mathrm{m}^{3} / \mathrm{d}$ & 12,000 & $12,000.12$ & $14,000.15$ \\
\hline Concentrate flow, $\mathrm{m}^{3} / \mathrm{d}$ & 22,285 & $22,285.59$ & $26,556.99$ \\
\hline Design salt rejection, $\%$ & 99.6 & 99.7 & 99.7 \\
\hline Recovery, $\%$ & 35 & 35 & 35 \\
\hline Permeate salinity, $\mathrm{mg} / \mathrm{L}$ & $>200$ & 98.92 & 99.59 \\
\hline Feed salinity, mg/L consumption & 36,204 & $37,993.95$ & $37,993.95$ \\
\hline $\begin{array}{l}\text { Specific } \\
\left(\mathrm{kWh} / \mathrm{m}^{3}\right)\end{array}$ & 8.492 & 5.48 & 5.47 \\
\hline
\end{tabular}

\section{Conclusions}

The productivity of the plant was increased with lower energy consumption and less number of membrane elements and pressure vessels (PVs) with insignificant modification to the piping system of the plant if needed. For reasonable comparison, the recovery of the plant was not increased to avoid massive modification to the plant. Additionally, the plant can be optimized to decrease the unit product cost to less than $2 \mathrm{kWh} / \mathrm{m}^{3}$ by replacing a conventional pretreatment and the energy recovery device with up-to-date techniques. In conclusion, latest improvements in membrane technology have made SWRO desalination more attractive because they had demonstrated significant enhancements in the rejection performance and the productivity of seawater reverse osmosis at lower feed pressure and less number of elements and pressure vessels, which will contribute in reduction of desalted water price, consequently, resulting in great improvement of the plant performance.

\section{References}

[1] H. Iskandar, M. Zhang, and J. Steven, "Simulation and Economic Optimization for a Brackish-Seawater Mixed Feed Reverse Osmosis Process Iskandar”, Singapore.

[2] U. Ezzeghni, and M. El-Bourawi, "Exergy analysis of a 10,000 $\mathrm{m}^{3} /$ day Tajoura SWRO desalination plant", The $1 \mathrm{st}$ International Conference on Chemical, Petroleum, and Gas Engineering (ICCPGE 2016) 20th - 22th December 2016, Alkhoms-Libya.

[3] I. El-Azizi, and A. Omran, "Design criteria of 10,000 $\mathrm{m}^{3} / \mathrm{d}$ SWRO desalination plant of Tajura, Libya", Desalination, vol. 153, pp. 273-270, 2002.

[4] M. Aboabboud, S. Elmasallati, and Y. Albriki., "Tajoura reverse osmosis seawater desalination plant operating and maintenance experience”, Desalination, vol. 203, pp. 119-133, 2007.

[5] M. Ashour, and S. Ghurbal, "Economics of seawater desalination in Libya”, Desalination, vol 165, pp. 215-218, 2004. 